\title{
Probing Fundamental Aspects of Synaptic Transmission with Strontium
}

\author{
Matthew A. Xu-Friedman and Wade G. Regehr \\ Department of Neurobiology, Harvard Medical School, Boston, Massachusetts 02115
}

Strontium is capable of supporting synaptic transmission, but release is dramatically different from that evoked in calcium. By measuring presynaptic strontium levels, we gain insight into the actions of strontium, which has implications for the identification of molecules involved in different aspects of synaptic transmission. We examined presynaptic divalent levels and synaptic release at the granule cell to stellate cell synapse in mouse cerebellar slices. We find that the prolonged duration of release and paired-pulse facilitation in the presence of strontium can be accounted for by the slower removal of strontium from the presynaptic terminal. Phasic and delayed release are both driven by strontium less effectively than by calcium, indicating that a heightened sensitivity to strontium is not a feature of the binding sites involved in facilitation and delayed release. We also find that the cooperativity for phasic release is 1.7 for strontium compared with 3.2 for calcium, suggesting that differential binding may help to identify the calcium sensor involved in phasic release.

Key words: delayed release; facilitation; phasic release; residual calcium; cooperativity; calcium sensor
Strontium can effectively substitute for calcium in driving synaptic transmission (Miledi, 1966; Dodge et al., 1969). This makes strontium a useful tool in studying calcium-dependent aspects of release. In this paper, we examine three such phenomena, phasic release, delayed release, and paired-pulse facilitation (PPF), each of which is perturbed significantly by the substitution of strontium for calcium.

Studies at many synapses have found that the EPSC peak is greatly reduced in strontium (Dodge et al., 1969; Mellow et al., 1982; Augustine and Eckert, 1984; Bain and Quastel, 1992; Goda and Stevens, 1994; Abdul-Ghani et al., 1996). The dominant component of the EPSC at such early times is attributable to phasic release, which is driven by a high presynaptic calcium concentration $(10-100 \mu \mathrm{M})$ local to the calcium channel pore $\left(\mathrm{Ca}_{\text {local }}\right)$ (Fogelson and Zucker, 1985; Simon and Llinas, 1985; Roberts et al., 1990; Heidelberger et al., 1994). Phasic release has a steep, power law dependence on the calcium concentration, which is thought to be attributable to $\mathrm{Ca}_{\text {local }}$ triggering vesicle fusion by binding to multiple low-affinity calcium sensors (Dodge and Rahamimoff, 1967). Because no significant change has been reported in the power law dependence in strontium (Meiri and Rahamimoff, 1971; Augustine and Eckert, 1984; Goda and Stevens, 1994), the decreased phasic component has been ascribed to lower affinity of the sensor driving phasic release for strontium.

The most noticeable effect of strontium is that individual release events continue for hundreds of milliseconds after presynaptic stimulation. This appears to be an enhancement of

Received Feb. 10, 2000; revised March 20, 2000; accepted March 28, 2000.

This work was supported by National Institutes of Health (NIH) Postdoctoral Training Grant 5T32 NS07112-19 to M.A.X.-F. and NIH Grant R01-NS32405-01 to W.G.R. We thank Bruce Bean, Adam Carter, Chinfei Chen, Jeremy Dittman, Anatol Kreitzer, and Kaspar Vogt for helpful comments. We also thank Michael Escobar and Raji Balasubramanian for statistical help.

Correspondence should be addressed to Dr. Wade G. Regehr, Department of Neurobiology, Harvard Medical School, 220 Longwood Avenue, Boston, MA 02115. E-mail: wade_regehr@hms.harvard.edu.

Copyright (c) 2000 Society for Neuroscience $0270-6474 / 00 / 204414-09 \$ 15.00 / 0$ delayed release, which consists of late release events driven by the low concentrations $(\ll 1 \mu \mathrm{M})$ of residual calcium $\left(\mathrm{Ca}_{\text {res }}\right)$ that persist in the terminal after the calcium channels close (Barrett and Stevens, 1972; Rahamimoff and Yaari, 1973; Zengel and Magleby, 1981; Zucker and Lara-Estrella, 1983; Van Der Kloot and Molgo, 1993). Delayed release is thought to result from $\mathrm{Ca}_{\text {res }}$ acting on a high-affinity sensor (Goda and Stevens, 1994; Atluri and Regehr, 1998; Zucker, 1999). One hypothesis for the enhancement of delayed release in strontium is that the sensor has a higher affinity for strontium (Goda and Stevens, 1994). This hypothesis has influenced the search for candidate molecules that act as high-affinity sensors (Li et al., 1995). An alternative hypothesis is that enhanced delayed release could arise from differences in presynaptic strontium regulation (Goda and Stevens, 1994; Rumpel and Behrends, 1999; Yawo, 1999). Recent measurements of presynaptic residual strontium levels $\left(\mathrm{Sr}_{\mathrm{res}}\right)$ have supported this view (Xu-Friedman and Regehr, 1999), but this study was limited by the inability to detect quantal events to determine release rates.

Strontium also enhances PPF (Zengel and Magleby, 1980). PPF is a form of short-term plasticity in which a presynaptic terminal stimulated twice at short intervals yields an enhanced second EPSC. PPF is similar to delayed release in that both are dependent on $\mathrm{Ca}_{\text {res }}$ (Van Der Kloot and Molgo, 1993; Kamiya and Zucker, 1994; Atluri and Regehr, 1996; Cummings et al., 1996), they have similar time courses (Zengel and Magleby, 1981), and both are enhanced in strontium. Thus, it has been proposed that they share the same underlying mechanism (Zucker and Lara-Estrella, 1983; Van Der Kloot and Molgo, 1993).

To clarify the differences between calcium- and strontiumevoked release, we measure $\mathrm{Sr}_{\text {res}}$, synaptic currents, and quantal release rates at cerebellar granule cell to stellate cell synapses. We find that the effects of strontium on delayed release and the time course of PPF are most easily explained by higher $\mathrm{Sr}_{\text {res }}$ and slower extrusion from the terminal. Its effects on phasic release and PPF amplitude are most likely attributable to lower affinity and cooperativity of strontium for the sensors involved in phasic 
release. One implication of these results is that strontium stoichiometry, but not binding affinity, may help in the identification of molecules involved in different aspects of synaptic transmission.

\section{MATERIALS AND METHODS}

The methods used are similar to those described previously (XuFriedman and Regehr, 1999). Briefly, we cut $300 \mu \mathrm{m}$ transverse slices from the vermis of the cerebellum of 14- to 21-d-old mice (ICR). Slices were incubated for $1 \mathrm{hr}$ at $33^{\circ} \mathrm{C}$ in artificial CSF (ACSF), composed of (in mM): $125 \mathrm{NaCl}, 26 \mathrm{NaHCO}_{3}, 1.25 \mathrm{NaH}_{2} \mathrm{PO}_{4}, 2.5 \mathrm{KCl}, 25$ glucose, 1 $\mathrm{MgCl}_{2}$, and $2 \mathrm{CaCl}_{2}$ bubbled with $95 \% \mathrm{O}_{2}-5 \% \mathrm{CO}_{2}(310 \mathrm{mOsm}) \mathrm{pH}$ 7.4. EPSCs were measured in whole-cell voltage-clamp recordings at $24^{\circ} \mathrm{C}$ from stellate cells in the distal half of the molecular layer, using 2-2.5 $\mathrm{M} \Omega$ electrodes containing (in $\mathrm{mm}$ ): $35 \mathrm{CsF}, 100 \mathrm{CsCl}, 10 \mathrm{HEPES}, 10$ EGTA, and 0.1 D-600 (290 mOsm), pH 7.2. Bicuculline $(20 \mu \mathrm{M})$ was added to the bath to block spontaneous inhibitory activity. We measured presynaptic residual divalent levels from parallel fibers using the $\mathrm{Ca}$ sensitive indicator magnesium green, as described previously (XuFriedman and Regehr, 1999). Changes in divalent levels were quantified as the percent change in fluorescence $(\% \Delta F / F)$. In some experiments, we observed a distinct, small, second peak $10-20 \mathrm{msec}$ after the first in the average EPSC or in the fluorescence transient, and these experiments were discarded from analysis.

To measure residual divalent levels or release in the presence of different calcium concentrations, standard ACSF was replaced by a similar bathing solution, except it contained decreased concentrations of $\mathrm{CaCl}_{2}$ and increased $\mathrm{MgCl}_{2}$, so that the total concentration of divalents was maintained at $3 \mathrm{~mm}$. For simplicity, we refer to these bathing solutions by their free calcium concentrations, i.e., $2 \mathrm{Ca}_{\mathrm{e}}, 1 \mathrm{Ca}_{\mathrm{e}}$, etc. To examine release in the presence of strontium, a different bathing solution was used to buffer contaminating calcium, composed of (in $\mathrm{mM}$ ): 120 $\mathrm{NaCl}, 34 \mathrm{NaHCO}_{3}, 1.25 \mathrm{Na}_{2} \mathrm{HPO}_{4}, 2.5 \mathrm{KCl}$, and 2 EGTA. $\mathrm{SrCl}_{2}$ and $\mathrm{MgCl}_{2}$ were then added to bring total divalents to $5 \mathrm{~mm}$. EGTA has a very high affinity for $\mathrm{Ca}^{2+}\left(K_{\mathrm{d}}\right.$ of $\left.\sim 100 \mathrm{nM}\right)$, which eliminates contaminating $\mathrm{Ca}^{2+}(\sim 6 \mu \mathrm{M})$. Most of the remaining EGTA binds $\mathrm{Sr}^{2+}\left(K_{\mathrm{d}}\right.$ of $\sim 30 \mu \mathrm{M})$, and very little binds $\mathrm{Mg}^{2+}$ because EGTA has a very low affinity for $\mathrm{Mg}^{2+}\left(K_{\mathrm{d}}\right.$ of $\left.\sim 15 \mathrm{~mm}\right)$. Thus, adding $4 \mathrm{mM} \mathrm{SrCl}_{2}$ and $1 \mathrm{~mm}$ $\mathrm{MgCl}_{2}$ leaves a free $\mathrm{Sr}^{2+}$ concentration of $2 \mathrm{~mm}$ and free $\mathrm{Mg}^{2+}$ concentration of $1 \mathrm{~mm}$. For simplicity, we refer to these bathing solutions by their free $\mathrm{Sr}^{2+}$ concentration, i.e., $2 \mathrm{Sr}_{\mathrm{e}}, 1 \mathrm{Sr}_{\mathrm{e}}$, etc. Most experiments were started in $2 \mathrm{Ca}_{\mathrm{e}}$ and then switched to one or more different calcium or strontium concentrations. Averages were computed after normalizing to the EPSC or peak $\Delta F / F$ in $2 \mathrm{Ca}_{\mathrm{e}}$. Six physiology experiments that switched from $2 \mathrm{Sr}_{\mathrm{e}}$ to $1,1.5$, or $3 \mathrm{Sr}_{\mathrm{e}}$ were normalized by the average peak in $2 \mathrm{Sr}_{\mathrm{e}}$. Physiology experiments were used for quantification only if they showed $>75 \%$ recovery after washout.

The fluorescence transients recorded in $\mathrm{Sr}_{\mathrm{e}}$ reflect residual strontium levels. Calcium released from internal stores is unlikely to contribute to these signals for several reasons. First, experiments using thapsigargin and ryanodine have no effect on $\mathrm{Ca}_{\mathrm{e}}$ fluorescence transients in rat parallel fibers (Sabatini and Regehr, 1995). Second, the rise times of the transients are fast, reaching a peak in a few milliseconds, whereas in systems in which calcium stores can be triggered by divalent influx, the rise times are slower and the peaks are broader (Lipp and Niggli, 1994). Third, there is close agreement in estimates of $\mathrm{Sr}_{\text {res }}$ based on indicators with different $K_{\mathrm{d}-\mathrm{Sr}} / K_{\mathrm{d}-\mathrm{Ca}}$ (Xu-Friedman and Regehr, 1999); this would not be the case if there were significant calcium contamination.

To count individual quantal events underlying evoked release, we examined the first derivative of each trace, and took events whose initial slopes exceeded some threshold. At low release frequency, this method successfully captured most events, as determined by visual inspection and by comparing the average EPSC against the convolution of event times with the average quantal event. Release rates were too high to detect all events during the first $5 \mathrm{msec}$ and are therefore blanked. For the average delayed release time course, we averaged data from eight experiments in $2 \mathrm{Ca}_{\mathrm{e}}$ by first subtracting the spontaneous release rate and then normalizing each experiment by the total number of detected events. Of those eight experiments, three had accompanying data in 2 $\mathrm{Sr}_{\mathrm{e}}$, which were scaled by the $\mathrm{Ca}_{\mathrm{e}}$ data recorded in the same experiment. In addition, we included seven further $2 \mathrm{Sr}_{\mathrm{e}}$ experiments that had no accompanying estimates of relative release rates in $\mathrm{Ca}_{e}$, by scaling them to the average number of release events in $\mathrm{Sr}_{\mathrm{e}}$, and then computing an overall average.

In studying phasic release, we used measurements of peak $\Delta F / F$ to estimate divalent influx in different concentrations of $\mathrm{Ca}_{\mathrm{e}}$ and $\mathrm{Sr}_{\mathrm{e}}$. For this approach to work, several preconditions must be met. First, the number of fibers stimulated in each condition must remain constant. Field potential measurements of the presynaptic action potential volley propagating along the parallel fibers have shown that this does not change significantly upon changing to $\mathrm{Sr}_{\mathrm{e}}$ (Xu-Friedman and Regehr, 1999). Second, the $\Delta F / F$ transient must be proportional to residual divalent levels without dye saturation, which is satisfied because peak residual divalent levels ( $<500 \mathrm{~nm}$ for calcium, $<1 \mu \mathrm{M}$ for strontium) are much less than the binding affinities for magnesium green $\left(K_{\mathrm{d}-\mathrm{Ca}}\right.$ of $6 \mu \mathrm{M}$ and $K_{\mathrm{d}-\mathrm{Sr}}$ of $33 \mu \mathrm{M}$ ). Third, peak residual divalent levels must be proportional to influx, i.e., the endogenous calcium buffer is not saturated. The endogenous buffer appears to have sufficiently low affinity for calcium that saturation is not significant (Sabatini and Regehr, 1998), and it has yet lower affinity for strontium (Xu-Friedman and Regehr, 1999). Thus, complications caused by fiber excitability, indicator saturation, and buffer saturation appear to be small, and we use the peak $\Delta F / F$ as an estimate of influx.

To examine the power law relationship between release and external divalent levels, we fit the data using a function of the following form: EPSC $=k\left([\text { divalent }]_{\mathrm{e}}\right)^{n}$. Thus, to statistically compare the cooperativities $(n)$ for strontium and calcium, we used the logarithmic form of the function and compared the slopes of the regression lines using a $t$ test (Glantz, 1997). This approach was also applied to the power law between release and internal divalent level. The contribution of measurement errors in divalent influx was considered negligible.

\section{RESULTS}

We examined the effects of strontium on synaptic transmission at the cerebellar granule cell to stellate cell synapse in 14- to 21-d-old mice. This preparation has the following advantages: there is no recurrent excitation (Palay and Chan-Palay, 1974), spontaneous inhibitory responses can be blocked with bicuculline (Llano et al., 1991), individual excitatory release events are easily detected (Atluri and Regehr, 1998; Chen and Regehr, 1999), spontaneous release is low, and presynaptic residual divalent levels can be measured (Regehr and Atluri, 1995; Xu-Friedman and Regehr, 1999).

We considered three aspects of synaptic transmission: phasic release, delayed release, and paired-pulse facilitation (Fig. 1). Phasic release is prominent in $2 \mathrm{mM} \mathrm{Ca}_{\mathrm{e}}$, as reflected in the fast decay time of the average EPSC evoked by stimulating the parallel fibers (Fig. 1A, top trace). There is a contribution from delayed release, and individual quantal release events can be seen in single trials (Fig. $1 A$, bottom traces). When the external calcium is replaced with $\mathrm{Sr}_{\mathrm{e}}$, phasic release is reduced (Fig. 1B, top trace), on average to $7.9 \pm 0.9 \%$ of control (mean \pm SE, $n=10$ experiments). However, delayed release is increased, as reflected in the slower decay of the average EPSC, and in the marked frequency of evoked quantal release for hundreds of milliseconds in individual trials (Fig. $1 \mathrm{~B}$, bottom traces). Additionally, when two stimuli are delivered $20 \mathrm{msec}$ apart in $\mathrm{Ca}_{\mathrm{e}}$, the second EPSC is facilitated (Fig. $1 C$, left). PPF was quantified as $A 2 / A 1-1$, where $A 1$ and $A 2$ are the peak amplitudes of the first and second EPSCs, respectively. In $\mathrm{Ca}_{\mathrm{e}}$, PPF was $1.4 \pm 0.1(n=28)$, but in $\mathrm{Sr}_{\mathrm{e}}$, PPF is larger (Fig. $1 C$, right), on average $3.3 \pm 0.2(n=22)$.

Thus, there are three major effects of strontium: delayed release is increased, phasic release is reduced, and paired-pulse facilitation is increased. These effects have been found previously at other synapses. However, at this synapse, we are able to measure strontium levels to provide insight into the underlying mechanisms.

\section{Delayed release}

To examine the effects of strontium on delayed release, we changed from $2 \mathrm{Ca}_{\mathrm{e}}$ to $2 \mathrm{Sr}_{\mathrm{e}}$. The decrease in phasic release and the increase in delayed release are fully reversible (Fig. 2A,B). 
A

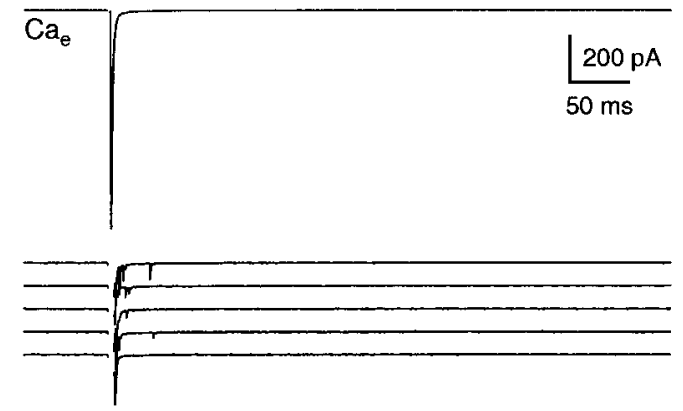

B

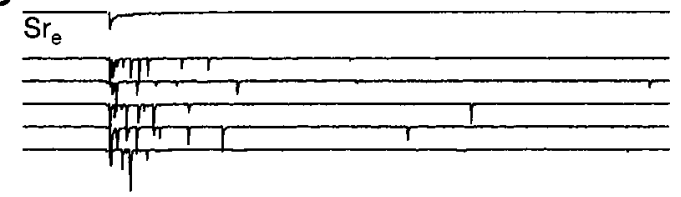

$\mathrm{C}$

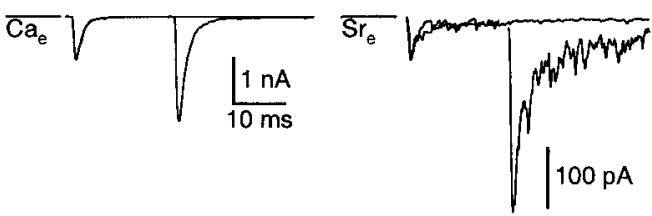

Figure 1. Synaptic release in $\mathrm{Ca}_{\mathrm{e}}(A)$ and $\mathrm{Sr}_{\mathrm{e}}(B)$. Top traces, Average EPSCs. Bottom five traces, Consecutive trials showing delayed release. In the single trials in $\mathrm{Ca}_{\mathrm{e}}$, the first $5 \mathrm{msec}$ of the EPSC have been blanked. In these and all following traces, the stimulus artifact has been removed. $C$, Paired-pulse facilitation in $\mathrm{Ca}_{\mathrm{e}}($ left $t)$ and $\mathrm{Sr}_{\mathrm{e}}$ (right). Average synaptic currents in response to one and two stimuli are overlaid, with responses to single stimuli scaled to the same height for comparison.

We quantified the rate of release by detecting individual release events. For individual trials, we recorded the times for all detected quanta and compiled them into a raster plot (Fig. $2 B$ ). To measure the average release rate over time, these events were binned into a peristimulus time histogram (PSTH) (Fig. 2C). The raster and PSTH plots both show that the evoked release rate is elevated over the spontaneous rate in $\mathrm{Ca}_{\mathrm{e}}$ for $\sim 100 \mathrm{msec}$ and in $\mathrm{Sr}_{\mathrm{e}}$ for $>500 \mathrm{msec}$. After $\sim 10 \mathrm{msec}$, evoked release rates in $\mathrm{Sr}_{\mathrm{e}}$ are considerably higher than in $\mathrm{Ca}_{\mathrm{e}}$.

We averaged data from several such experiments (Fig. 2D). First, we normalized all experiments to the same total number of events in $\mathrm{Ca}_{\mathrm{e}}$ and then scaled the accompanying trials in $\mathrm{Sr}_{\mathrm{e}}$ accordingly. Delayed release shows a double-exponential decay in $\mathrm{Ca}_{\mathrm{e}}\left(\tau_{1}\right.$ of $6.4 \mathrm{msec}, \tau_{2}$ of $\left.64 \mathrm{msec} ; n=8\right)$ and $\mathrm{Sr}_{\mathrm{e}}\left(\tau_{1}\right.$ of $20 \mathrm{msec}$, $\tau_{2}$ of $\left.89 \mathrm{msec} ; n=10\right)$. After the first $50 \mathrm{msec}$, the rate of release in $\mathrm{Sr}_{\mathrm{e}}$ is $\sim 10$ times greater than that in $\mathrm{Ca}_{\mathrm{e}}$.

Release in strontium versus calcium was analyzed quantitatively in a previous study, which described it as a combination of two components, a fast component (equivalent to phasic release) that was greater in calcium, and a slow component (equivalent to delayed release) that was greater in strontium (Goda and Stevens, 1994). One explanation for these findings was that the affinity of the calcium sensors driving release may be different for strontium (Goda and Stevens, 1994). In particular, the low-affinity sensor responsible for phasic release may have a lower affinity for strontium, and the high-affinity sensor responsible for delayed release may have a higher affinity for strontium. An alternative mechanism that could also influence the time course of delayed release
A

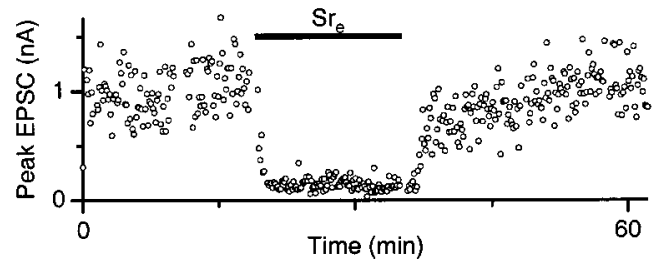

B

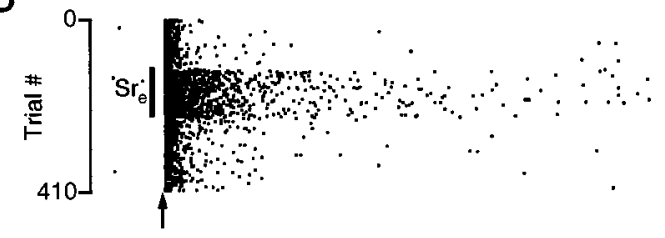

C

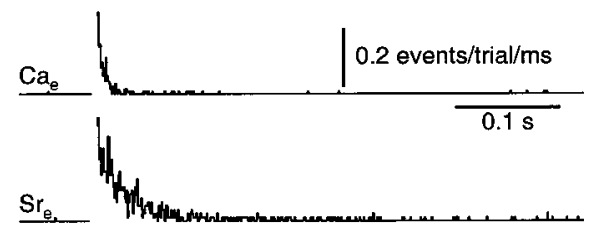

D

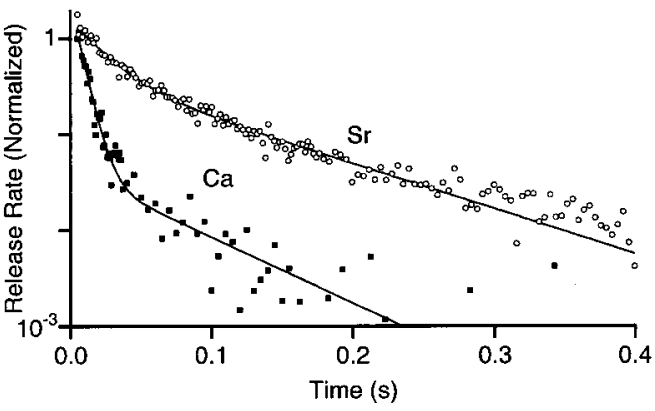

Figure 2. Quantifying delayed release in $\mathrm{Ca}_{\mathrm{e}}$ and $\mathrm{Sr}_{\mathrm{e}} \cdot A$, Experimental time course for the same experiment as in Figure 1. Circles represent the EPSC peak amplitudes for each trial. $B$, Raster plot of delayed release over the course of the experiment in $A$. Dots on a given line represent detected quanta for each trial. $C$, PSTH of release events shown in $B . D$, Semi-log plot of the average PSTH from eight experiments for $\mathrm{Ca}_{\mathrm{e}}$ and 10 for $\mathrm{Sr}_{\mathrm{e}}$, fit with an equation of the following form: release $=A e^{-t / \tau_{I}}+$ $B e^{-t / \tau_{2}}$. For $\mathrm{Ca}_{\mathrm{e}}, A=2.47, \tau_{1}=6.4 \mathrm{msec}, \mathrm{B}=0.04$, and $\tau_{2}=64 \mathrm{msec}$. For $\mathrm{Sr}_{\mathrm{e}}, A=0.43, \tau_{1}=21 \mathrm{msec}, B=1.17$, and $\tau_{2}=92 \mathrm{msec}$. The average $\mathrm{Ca}_{\mathrm{e}}$ PSTH is scaled so that the release rate equals 1 at $5 \mathrm{msec}$ after the start of the EPSC, and the $\mathrm{Sr}_{\mathrm{e}}$ PSTH is scaled accordingly.

is that $\mathrm{Sr}_{\text {res }}$ dynamics could differ considerably from $\mathrm{Ca}_{\text {res }}$, because of differences in buffering and extrusion (Barrett and Stevens, 1972; Goda and Stevens, 1994; Xu-Friedman and Regehr, 1999). The first explanation has gained dominance in the literature. However, to distinguish between these alternatives, it is important to take into account measurements of the time course of $\mathrm{Ca}_{\text {res }}$ and $\mathrm{Sr}_{\text {res. }}$.

We have previously applied conventional fluorometric $\mathrm{Ca}_{\text {res }}$ measurement techniques toward quantifying $\mathrm{Sr}_{\text {res }}$ (Xu-Friedman and Regehr, 1999). Here, we used magnesium green as the fluorophore (Zhao et al., 1996) for two reasons. First, it has a low affinity for strontium and calcium compared with the amplitudes of $\mathrm{Ca}_{\text {res }}$ and $\mathrm{Sr}_{\text {res }}$ after single stimuli (see Materials and Methods) (Regehr and Atluri, 1995; Xu-Friedman and Regehr, 1999), such that the time course of fluorescence transients linearly reflects the 


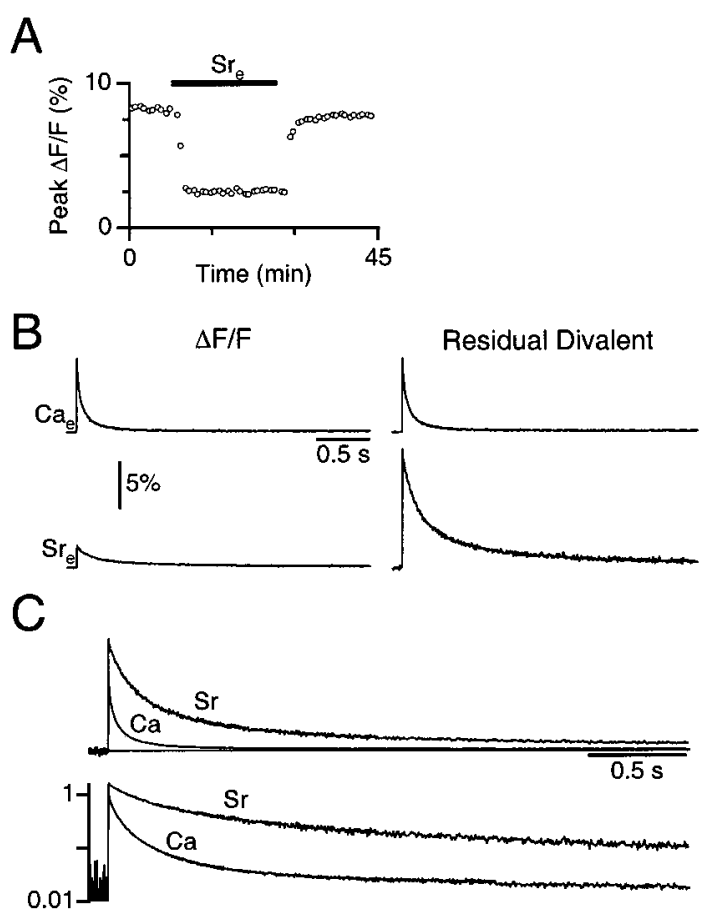

Figure 3. Quantifying residual calcium and strontium using magnesium green. $A$, Representative experiment changing from $2 \mathrm{mM} \mathrm{Ca}_{\mathrm{e}}$ to $2 \mathrm{mM}$ $\mathrm{Sr}_{\mathrm{e}}$. Circles represent the peak fluorescence change after parallel fiber stimulation. $B$, Left, Average $\Delta F / F$ transients recorded during the experiment in $A$ in $\mathrm{Ca}_{\mathrm{e}}$ (top) and $\mathrm{Sr}_{\mathrm{e}}$ (bottom). Right, Residual calcium and strontium transients. Residual strontium is plotted relative to residual calcium by correcting the $\Delta F / F$ signal for fluorophore affinity. $C$, Average residual divalent transients (32 experiments for $\mathrm{Ca}_{\mathrm{e}}, 9$ for $\mathrm{Sr}_{\mathrm{e}}$ ). Top trace, Linear plot. Bottom trace, Semi-log plot.

time course of divalent transients. Second, magnesium green shows large percent fluorescence changes upon stimulation, yielding a high signal-to-noise ratio. Contamination of the fluorescence signal by magnesium is not significant, because $\Delta F / F$ measurements for the low-affinity calcium indicator fura-2FF, which has no measurable magnesium affinity, did not differ significantly in their time course (Xu-Friedman and Regehr, 1999).

When the bathing solution is changed from $\mathrm{Ca}_{\mathrm{e}}$ to $\mathrm{Sr}_{\mathrm{e}}$, there is a drop in the peak fluorescence change in response to stimulation (Fig. 3A, B, left). We converted these fluorescence transients into the relative concentrations of residual divalents by taking into account the binding affinities of magnesium green for calcium versus strontium (i.e., by multiplying by $\left.5.5=K_{\mathrm{d}-\mathrm{Sr}} / K_{\mathrm{d}-\mathrm{Ca}}\right)(\mathrm{Xu}-$ Friedman and Regehr, 1999). After this correction, it is clear that $\mathrm{Sr}_{\text {res }}$ is greater than $\mathrm{Ca}_{\text {res }}$, and persists much longer in the terminal (Fig. 3B, right). We averaged together several such experiments and found that peak $\mathrm{Sr}_{\text {res }}$ is $1.60 \pm 0.02(n=16)$ times peak $\mathrm{Ca}_{\text {res }}$ (Fig. $3 C$ ), which is probably a result of a combination of greater presynaptic influx and lower affinity of the endogenous buffer for strontium compared with calcium. $\mathrm{Sr}_{\text {res }}$ then decays approximately five times more slowly than $\mathrm{Ca}_{\text {res }}\left(\mathrm{Sr}_{\text {res }}\right.$ half decay time, $165 \pm 5 \mathrm{msec}, n=8 ; \mathrm{Ca}_{\text {res }}, 31 \pm 0.4 \mathrm{msec}, n=17$ ), probably because of lower efficacy of extrusion.

We show the average delayed release rate as a function of average residual divalent concentration in Figure 4. In $\mathrm{Ca}_{\mathrm{e}}$, two components of delayed release with different dependencies on calcium are evident (Fig. 4B) (Atluri and Regehr, 1998), whereas only one component is visible in strontium. This is probably
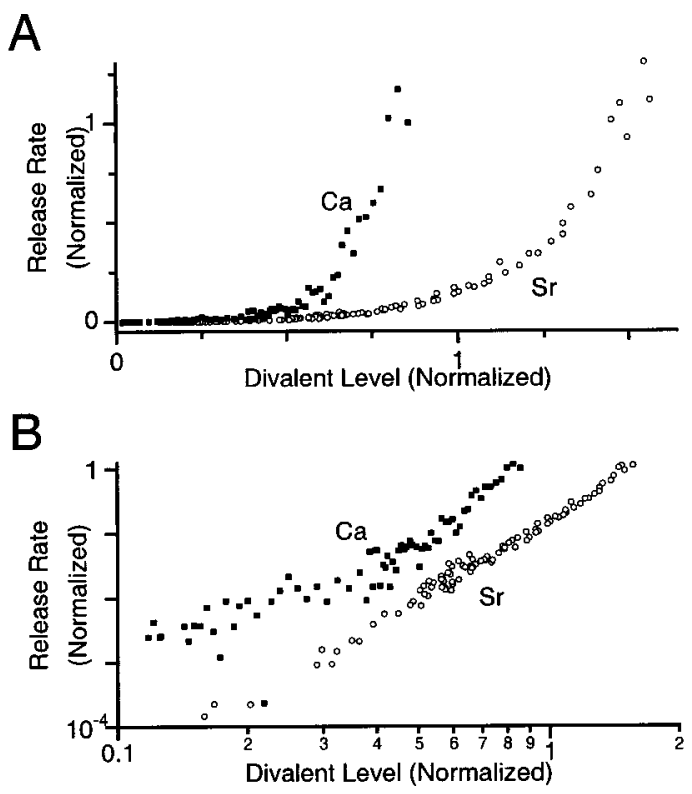

Figure 4. Delayed release as a function of residual divalent levels, displayed linearly $(A)$ and on a $\log -\log$ plot $(B)$, using data in Figures $2 D$ and $3 C$.

because release rates have declined too much at low strontium concentrations to adequately quantify a second component. If release rates depended solely on instantaneous divalent levels, it should be possible to use these curves to determine the power law dependence of release and to compare release driven by strontium and calcium. However, previous work has shown that release rates also depend on the kinetics of a process driven by divalent binding (Atluri and Regehr, 1998). Therefore, fits have not been included, and it is difficult to interpret the apparent difference in the steepness of divalent dependence for $\mathrm{Sr}_{\mathrm{e}}$ and $\mathrm{Ca}_{\mathrm{e}}$.

It is clear, however, that overall concentrations of divalent, release rates in $\mathrm{Ca}_{\mathrm{e}}$ are 5-10 times greater than in $\mathrm{Sr}_{\mathrm{e}}$. Thus, strontium is less effective at driving release. The higher levels of delayed release observed in Figure $2 D$ are most simply explained by the high and prolonged presence of $\mathrm{Sr}_{\text {res }}$ in the presynaptic terminal.

\section{Phasic release}

We examined the effect of strontium on phasic release by determining the power law relationship between the peak EPSC and the magnitude of presynaptic divalent influx. Measurements of peak $\mathrm{Ca}_{\text {res }}$ or $\mathrm{Sr}_{\text {res }}$ in different $\mathrm{Ca}_{\mathrm{e}}$ or $\mathrm{Sr}_{\mathrm{e}}$ were used as an indication of influx (see Materials and Methods). We began each experiment in $2 \mathrm{Ca}_{\mathrm{e}}$ and switched to test solutions containing different concentrations of $\mathrm{Ca}_{\mathrm{e}}$ or $\mathrm{Sr}_{\mathrm{e}}$ (Fig. 5A,B). To compute average results from the test solutions, they were first normalized by the peak in $2 \mathrm{Ca}_{\mathrm{e}}$. The relationship between $\mathrm{Ca}_{\mathrm{e}}$ and peak $\mathrm{Ca}_{\text {res }}$ was sublinear, indicating saturation of influx (Fig. 5A,C) (Mintz et al., 1995). In $\mathrm{Sr}_{\mathrm{e}}$, however, we saw no evidence of influx saturation (Fig. $5 B, C$ ).

We estimated peak release rates using the EPSC peak amplitude in different $\mathrm{Ca}_{\mathrm{e}}$ and $\mathrm{Sr}_{\mathrm{e}}$ (Fig. 6A,B). These data were fit to a power law relationship: EPSC $=k\left([\text { divalent }]_{\mathrm{e}}\right)^{n}($ Fig. $6 C)$. The values of $n$ for calcium $(2.1 \pm 0.2, n=11)$ and strontium $(1.9 \pm$ $0.1, n=28)$ did not differ significantly $(t=0.54, \mathrm{df}=35, p>0.5)$. However, this traditional analysis can be misleading because influx and external divalent concentrations are not linearly re- 
A

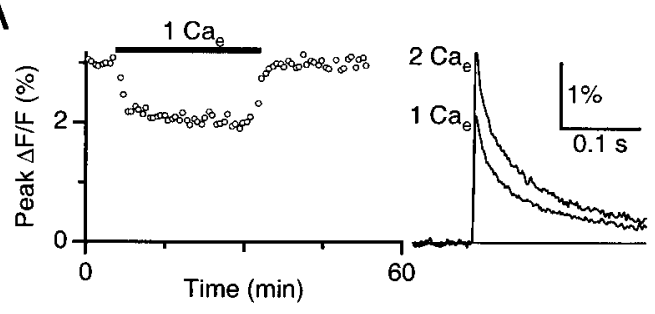

B

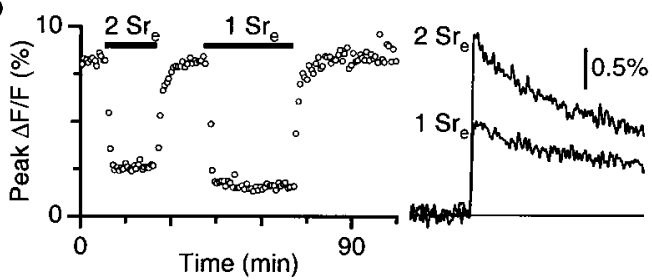

C

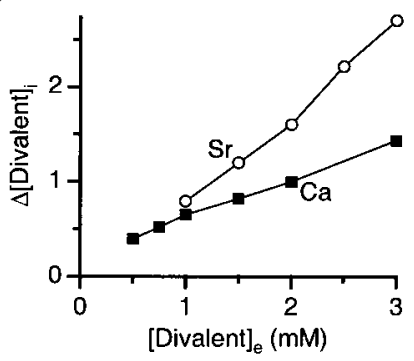

Figure 5. Peak $\mathrm{Ca}_{\text {res }}$ and $\mathrm{Sr}_{\text {res }}$ in different concentrations of $\mathrm{Ca}_{\mathrm{e}}$ and $\mathrm{Sr}_{\mathrm{e}}$. $A$, Representative experiment changing from $2 \mathrm{Ca}_{\mathrm{e}}$ to $1 \mathrm{Ca}_{\mathrm{e}}$. Left, Experimental time course. Each circle represents the peak $\Delta F / F$ after parallel fiber stimulation. Right, Average $\Delta F / F$ transients. $B$, Representative experiment changing from $2 \mathrm{Ca}_{\mathrm{e}}$ to $2 \mathrm{Sr}_{\mathrm{e}}$ and $1 \mathrm{Sr}_{\mathrm{e}}$. Left, Experimental time course as in $A$. Right, Average $\Delta F / F$ transients. $C$, Peak residual calcium and strontium in different external divalent concentrations, after correcting the peak $\Delta F / F$ for fluorophore affinity. Each point is the average of 4-10 experiments. Error bars are SE and are obscured by the marker.

lated (Fig. 5C). When we use our measure of relative divalent influx and fit the data using the revised relationship (EPSC $=k$ $\left.\left([\text { divalent }]_{\mathrm{i}}\right)^{n}\right)$, the power law exponent changes significantly: $3.2 \pm 0.2$ for calcium versus $1.7 \pm 0.1$ for strontium (Fig. $6 D)(t=$ 2.49, df $=35, p<0.02$ ).

\section{Paired-pulse facilitation}

We examined the effect of substituting strontium for calcium on the amplitude and time course of PPF. The amplitude of PPF increases when the external solution is changed from $\mathrm{Ca}_{\mathrm{e}}$ to $\mathrm{Sr}_{\mathrm{e}}$ (Fig. 1C). One possible explanation for this is that a special calcium sensor is responsible for facilitation and that $\mathrm{Sr}_{\mathrm{res}}$ binds to it more effectively than to $\mathrm{Ca}_{\text {res }}$, thereby producing prominent facilitation. Another possible explanation is that a decrease in the initial probability of release enhances PPF, as has been found in many studies (Fig. 7A) (Feng, 1941; Rahamimoff, 1968; Creager et al., 1980; McNaughton, 1982; Manabe et al., 1993; Dobrunz and Stevens, 1997). Experiments in the presence of strontium change both the residual divalent signal available to drive facilitation and the initial probability of release. To determine which of these factors leads to the enhancement of PPF in $\mathrm{Sr}_{e}$, we manipulated residual divalent levels and release probability by changing the concentrations of $\mathrm{Ca}_{\mathrm{e}}$ and $\mathrm{Sr}_{\mathrm{e}}$.

We measured the amplitude of PPF using pairs of stimulation pulses separated by $20 \mathrm{msec}$. In $2 \mathrm{Ca}_{\mathrm{e}}, \mathrm{PPF}$ was $1.4 \pm 0.1(n=28)$
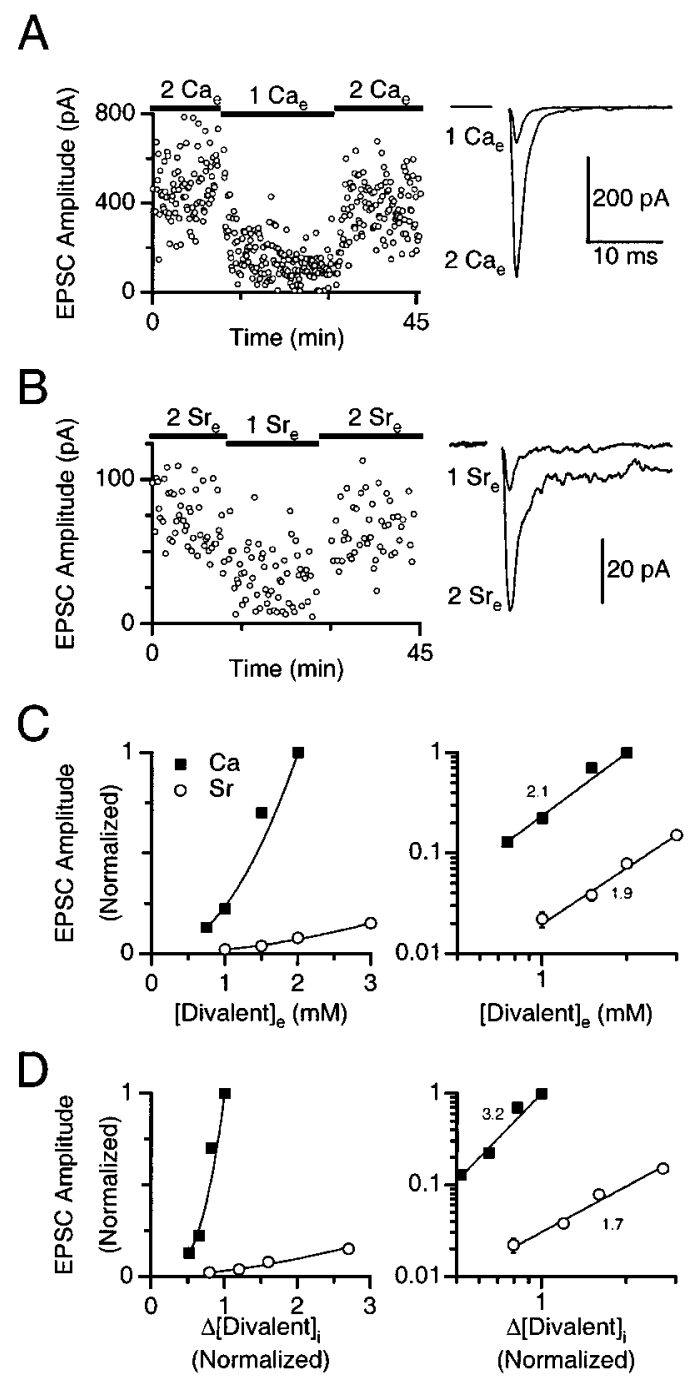

Figure 6. Peak EPSC in different concentrations of $\mathrm{Ca}_{\mathrm{e}}$ and $\mathrm{Sr}_{\mathrm{e}}$. Representative experiments changing from $2 \mathrm{Ca}_{\mathrm{e}}$ to $1 \mathrm{Ca}_{\mathrm{e}}(A)$ and $2 \mathrm{Sr}_{\mathrm{e}}$ to $1 \mathrm{Sr}_{\mathrm{e}}$ (B). Left, Experimental time course. Circles represent the peak EPSC after parallel fiber stimulation. Right, Average EPSCs. $C$, Peak EPSC as a function of external divalent levels (left, linear plot; right, log-log plot). EPSC amplitudes are normalized to $2 \mathrm{Ca}_{\mathrm{e}}$. Each point is the average of 3-5 experiments for $\mathrm{Ca}$ and 5-10 for Sr. Error bars are SE and are obscured by the marker. Lines are best fits to an equation of the following form: EPSC $=k\left([\text { divalent }]_{\mathrm{e}}\right)^{n}$, and the value for $n$ is shown next to the fit. $D$, Peak EPSC as a function of peak residual levels (left, linear plot; right, $\log -\log$ plot). Lines are best fits to an equation of the following form: $\mathrm{EPSC}=k\left(\Delta\left[\text { divalent }_{\mathrm{i}}\right)^{n}\right.$.

(Fig. 7A, left), whereas in $2 \mathrm{Sr}_{\mathrm{e}}$, PPF was much larger, $3.3 \pm 0.2$ $(n=22)$ (Fig. $7 B$, left $)$. However, when the divalent concentration was reduced, PPF in $1 \mathrm{Ca}_{\mathrm{e}}$ increased significantly to $3.1 \pm 0.5$ $(n=4)$ (Fig. 7A, right), and $\mathrm{PPF}$ in $1 \mathrm{Sr}_{\mathrm{e}}$ remained unchanged $(2.7 \pm 0.3, n=8)$ (Fig. $7 B$, right). Thus, although there is a considerable difference between the magnitude of PPF in $2 \mathrm{Ca}_{\mathrm{e}}$ versus $2 \mathrm{Sr}_{\mathrm{e}}$, this difference decreases as the concentration of divalents is reduced (Fig. 7C). A plot of the magnitude of PPF as a function of peak residual divalent concentration (Fig. 7D) reveals that, as peak $\mathrm{Ca}_{\text {res }}$ increases, $\mathrm{PPF}$ in $\mathrm{Ca}_{\mathrm{e}}$ decreases, but as peak $\mathrm{Sr}_{\text {res }}$ increases, PPF in $\mathrm{Sr}_{\mathrm{e}}$ remains unchanged. These findings indicate that the amplitude of PPF at this synapse does not simply reflect differences in the residual divalent signals in $\mathrm{Sr}_{\mathrm{e}}$ 

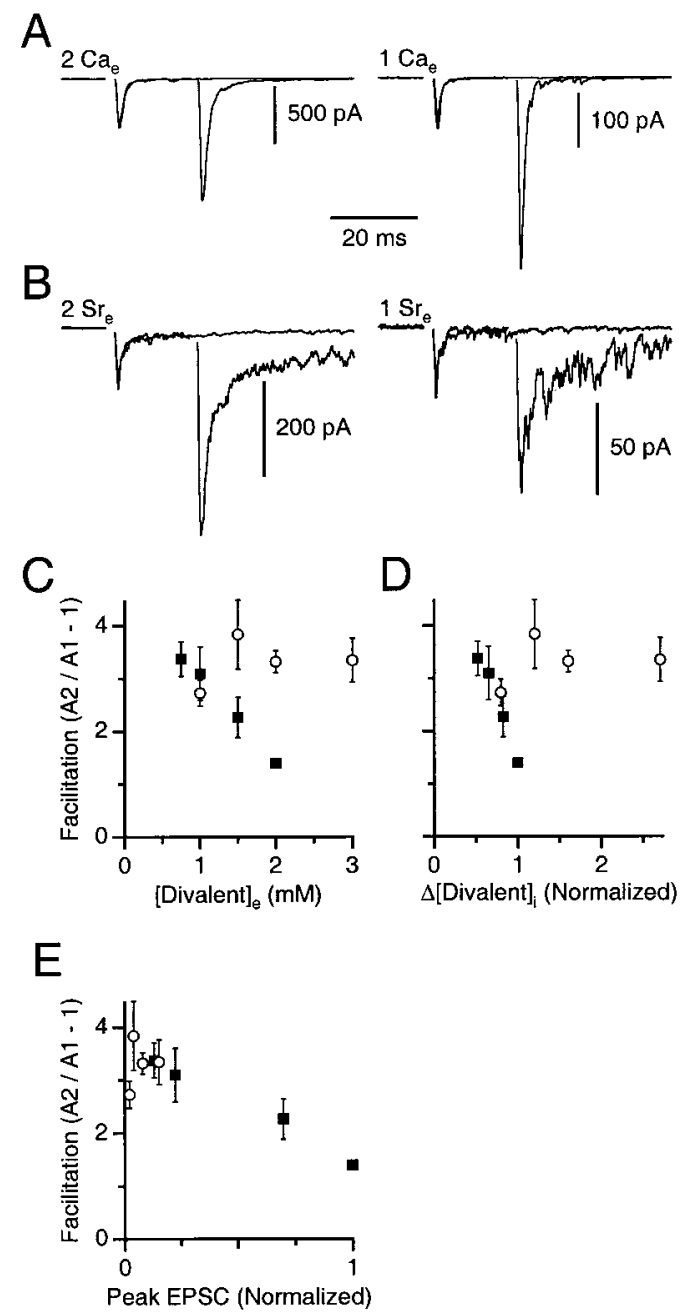

Figure 7. Facilitation in strontium. Average traces from two representative experiments measuring PPF in $1 \mathrm{Ca}_{\mathrm{e}}$ and $2 \mathrm{Ca}_{\mathrm{e}}(A)$ and $1 \mathrm{Sr}_{\mathrm{e}}$ and 2 $\mathrm{Sr}_{\mathrm{e}}(B)$. Average synaptic currents in response to one and two stimuli are overlaid, with responses to single stimuli scaled to the same height across all panels for comparison. Average peak PPF is plotted as a function of $\mathrm{Ca}_{\mathrm{e}}$ and $\mathrm{Sr}_{\mathrm{e}}(C)$, peak $\mathrm{Ca}_{\text {res }}$ and $\mathrm{Sr}_{\mathrm{res}}(D)$, and EPSC peak amplitude $(E)$. Residual divalent data are from Figure 5, and peak EPSCs are from Figure 6.

and $\mathrm{Ca}_{\mathrm{e}}$, and that the initial probability of release must also be considered.

When the initial probability of release is taken into account (Fig. $7 E$ ), there is no fundamental difference between the magnitude of PPF in $\mathrm{Sr}_{\mathrm{e}}$ and $\mathrm{Ca}_{\mathrm{e}}$. The magnitude of PPF is $\sim 3$ when the probability of release is low, whether in $1 \mathrm{Ca}_{\mathrm{e}}$ or in 1 to $3 \mathrm{~mm}$ $\mathrm{Sr}_{\mathrm{e}}$. The magnitude of PPF decreases only when the probability of release increases, as when $\mathrm{Ca}_{\mathrm{e}}$ is larger than $1 \mathrm{~mm}$. Thus, the high levels of PPF in $\mathrm{Sr}_{\mathrm{e}}$ can be accounted for by the low initial probability of release in $\mathrm{Sr}_{\mathrm{e}}$. It not necessary to hypothesize that the calcium sensor involved in facilitation is particularly sensitive to strontium.

We next examined the time course of PPF in the presence of strontium. Previous studies have shown that PPF is prolonged in $\mathrm{Sr}_{\mathrm{e}}$ compared with $\mathrm{Ca}_{\mathrm{e}}$ (Zengel and Magleby, 1980; Van Der Kloot and Molgo, 1993). Although the reason for the protracted time course was not clear, several possible explanations are apparent after considering the role of calcium in facilitation. Com- parisons between the decay of PPF and of $\mathrm{Ca}_{\text {res }}$ have suggested that PPF is produced by calcium binding to a high-affinity receptor but with slow kinetics (Atluri and Regehr, 1996). Thus, the time course of facilitation in $\mathrm{Ca}_{\mathrm{e}}$ reflects in part the time course of $\mathrm{Ca}_{\text {res }}$ and in part a slow calcium-driven process, which produces a lag between the decay of $\mathrm{Ca}_{\text {res }}$ and of PPF. The prolongation of PPF in $\mathrm{Sr}_{\mathrm{e}}$ could arise from slower kinetics of strontium binding to the sensors responsible for facilitation or from slower extrusion of $\mathrm{Sr}_{\mathrm{res}}$ from the terminal compared with $\mathrm{Ca}_{\text {res }}$

We measured the time course of PPF at the granule cell to stellate cell synapse in $2 \mathrm{Ca}_{\mathrm{e}}$ and $2 \mathrm{Sr}_{\mathrm{e}}$ (Fig. $8 A$ ) by varying the interval $(\Delta t)$ between pairs of pulses. In $\mathrm{Ca}_{\mathrm{e}}$, PPF returns to initial values by $\Delta t=500 \mathrm{msec}$ (Fig. $8 A$, top ), but in $\mathrm{Sr}_{\mathrm{e}}$ it remains elevated until after $\Delta t=750 \mathrm{msec}$ (Fig. $8 A$, bottom). On average, PPF was higher in $\mathrm{Sr}_{\mathrm{e}}$ than in $\mathrm{Ca}_{\mathrm{e}}$ for at least $1 \mathrm{sec}$ (Fig. 8B). This is not just a result of the higher levels of PPF observed in $2 \mathrm{Sr}_{\mathrm{e}}$, because when the time course of facilitation is normalized for peak PPF, facilitation persists longer in $\mathrm{Sr}_{\mathrm{e}}$ (Fig. 8C). Fitting the PPF curves with an exponential function, the $\tau_{\text {decay }}$ in $\mathrm{Ca}_{\mathrm{e}}$ was $175 \pm 24 \operatorname{msec}(n=3)$ and in $2 \mathrm{Sr}_{\mathrm{e}}$ was $480 \pm 60 \mathrm{msec}(n=5)$.

To determine the basis for this prolongation, we directly compare the time courses of residual divalent levels and of PPF (Fig. $8 D$ ). In $\mathrm{Ca}_{\mathrm{e}}$, we observe the expected lag between the decay of PPF and of $\mathrm{Ca}_{\text {res }}$ (Fig. 8D, top). In $\mathrm{Sr}_{\mathrm{e}}$, the time courses of PPF and $\mathrm{Sr}_{\text {res }}$ match each other much more closely (Fig. 8D, bottom). This suggests that the primary determinant of the time course of $\mathrm{PPF}$ in $\mathrm{Sr}_{\mathrm{e}}$ is the time course of $\mathrm{Sr}_{\text {res }}$, which is prolonged by the slower removal of strontium from the presynaptic terminal.

\section{DISCUSSION}

Our studies have provided new insights into calcium-driven aspects of synaptic transmission. Contrary to the accepted view, we find that the prominent delayed release in $\mathrm{Sr}_{\mathrm{e}}$, a characteristic that has been widely used in the study of synaptic transmission, is a consequence of less efficient buffering and extrusion of strontium from the presynaptic terminal. Thus, high sensitivity to strontium is not a hallmark of the calcium sensor involved in facilitation and delayed release. Our studies of the strontium dependence of phasic release confirm that strontium triggers phasic release less effectively than does calcium. However, in contrast to previous studies, by measuring presynaptic strontium influx we find that strontium also triggers phasic release with a lower cooperativity than calcium. This feature will be important in identifying and characterizing the calcium sensor involved in phasic release.

\section{Strontium dependence of phasic release}

Our studies of the strontium dependence of phasic release provide important insights into the calcium sensors that trigger fast synaptic transmission. In agreement with studies of other synapses, we found that the EPSC peak is greatly reduced in strontium. Traditionally, this has been interpreted as being attributable to the sensor having lower affinity for strontium than for calcium. However, our measurements of presynaptic strontium influx additionally show that strontium triggers phasic release with a lower cooperativity than does calcium ( $n=1.7$ for strontium and $n=$ 3.2 for calcium). This indicates that the effect of strontium on phasic release is more complicated than was previously envisioned.

To understand the implications of this difference in cooperativity, it is useful to consider the power law relationship between calcium and release. A widespread feature of fast synaptic trans- 
Figure 8. Effect of strontium on the time course of facilitation. $A$, Average traces from two representative experiments measuring the time course of decay of facilitation in $2 \mathrm{Ca}_{\mathrm{e}}$ (top traces) and $2 \mathrm{Sr}_{\mathrm{e}}$ (bottom traces). The first EPSC is the average response to the first stimulus, after which there was a variable delay followed by the second stimulus. Dashed lines over the last facilitated EPSC indicate the peak amplitude of the first EPSC. $B$, Time course of decay of PPF in $2 \mathrm{Ca}_{\mathrm{e}}(n=$ 3 experiments $)$ and $2 \mathrm{Sr}_{\mathrm{e}}(n=5$ experiments). $C$, Time course normalized to peak PPF and fit to an equation of the following form: PPF = $e^{-\Delta t / \tau}$, with $\tau_{\mathrm{Ca}}=175 \pm 24 \mathrm{msec}$ and $\tau_{\mathrm{Sr}}=480 \pm 60 \mathrm{msec}$. $D$, Comparison of the time courses of PPF and residual divalent concentration.
A
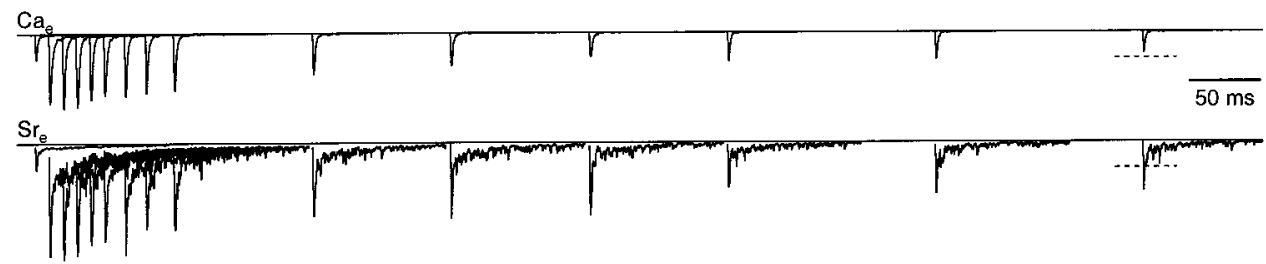

B

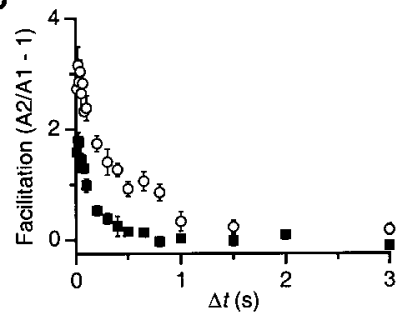

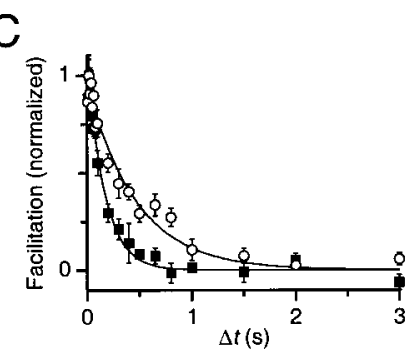

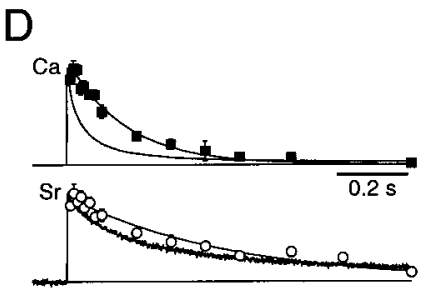

mission is that release is steeply dependent on extracellular calcium levels, with a power law relationship of $n=2-4$ at most synapses (Dodge and Rahamimoff, 1967; Augustine et al., 1985; Lando and Zucker, 1994; Mintz et al., 1995; Borst and Sakmann, 1996; Sabatini and Regehr, 1997). This power law relationship is usually interpreted as multiple calcium ions binding to the sensors that trigger release. Most previous studies did not reveal differences in the cooperativity for calcium and strontium (Meiri and Rahamimoff, 1971; Augustine and Eckert, 1984; Goda and Stevens, 1994), suggesting that the same number of strontium ions as calcium ions are required to bind to trigger release. However, technical limitations in these experiments may have obscured differences in the power laws. For example, most of these studies were unable to take into account the relationship between the extracellular divalent concentration and influx. We found that it was necessary to measure intracellular calcium and strontium levels to estimate influx to adequately estimate the power law relationships, because external divalent concentrations and influx are not necessarily linearly related (Fig. 5C).

This differential cooperativity will be important in identifying the calcium sensor involved in phasic release. Further experiments are required to evaluate possible contributions to differential cooperativity, including endogenous buffer saturation near the channel, lower strontium permeability through channels more strongly coupled to release, and differences in the kinetics of binding to the release sensor. However, the simplest interpretation of the lower cooperativity for strontium than calcium is that fewer strontium ions bind to the sensors that trigger release, and when they do bind they are less effective at triggering release. Although this hypothesis needs to be investigated further, a decrease in the number of strontium ions binding is consistent with preliminary structural data of the $\mathrm{C} 2 \mathrm{~A}$ domain of synaptotagmin I, which has been hypothesized to serve as the calcium sensor involved in phasic release. This domain binds three calcium ions but only one strontium ion (J. Garcia, T.C. Südhof, and J. Rizo, personal communication), which would be difficult to reconcile with calcium and strontium having the same cooperativity for phasic release. Similar studies of strontium and calcium binding to other presynaptic calcium binding proteins could provide further insight into the identity of the calcium sensors involved in phasic release. In addition, if the binding of fewer strontium ions can trigger release, this will provide an important means of studying how divalent ion binding produces the confor- mational changes involved in vesicle fusion. Other possible influences on cooperativity should also be investigated.

\section{Mechanism responsible for prominent delayed release in strontium}

The most widespread use of strontium in the study of synaptic transmission is to desynchronize release to allow examination of the amplitude of evoked quantal events (Abdul-Ghani et al., 1996; Oliet et al., 1996; Choi and Lovinger, 1997; Morishita and Alger, 1997; Otis et al., 1997; Behrends and ten Bruggencate, 1998; Lévénès et al., 1998; Bekkers and Clements, 1999; Bellingham and Walmsley, 1999). Our studies suggest that the prevailing hypothesis for this aspect of synaptic transmission needs to be revised. Previously, prominent delayed release in the presence of strontium had been ascribed to a specialized calcium sensor that binds strontium with higher affinity than it binds calcium (Goda and Stevens, 1994). Although we see a similar enhancement of delayed release, we find that, when the residual divalent levels in the presynaptic terminals are taken into account, delayed release is actually much lower for strontium compared with calcium over all concentrations. These high sustained levels of strontium are likely a consequence of less efficient buffering and extrusion of strontium from the presynaptic terminal.

\section{Mechanism responsible for effects on PPF in the presence of strontium}

Our measurements of residual strontium levels and the initial probability of release suggest that the explanation for the effects of strontium on the amplitude and time course of facilitation must also be revised. In agreement with previous studies (Zengel and Magleby, 1980; Van Der Kloot and Molgo, 1993), we found that the time course of facilitation was prolonged in the presence of strontium compared with calcium. Just as for delayed release, this is likely a consequence of the prolonged elevation of strontium in the presynaptic terminal because of the close agreement between the time courses of presynaptic strontium and facilitation.

We also observed an increase in the amplitude of PPF. One interpretation of this result is that the increased amplitude of PPF in the presence of strontium reflects the preferential binding of strontium to the calcium sensors responsible for facilitation. Our results suggest an alternative interpretation that is based on the widely observed contribution of the initial probability of release to the amplitude of facilitation. Facilitation is much more prom- 
inent in strontium than in calcium, except when calcium levels are low. These results suggest that the major effect of strontium on the amplitude of facilitation is not a direct consequence of strontium binding preferentially to the release sites involved in facilitation. Rather, it is a consequence of strontium reducing the initial probability of release, which indirectly increases the amplitude of facilitation.

One implication of these findings is that, as for delayed release, strontium acts through the same machinery that calcium does but with lower affinity. Because many calcium-dependent biological processes are driven less well by strontium, this is not likely to be a useful criterion for identifying the high-affinity calcium sensors involved in facilitation.

Overall, this study highlights the advantages of a comprehensive approach in the study of synaptic transmission. This includes the measurement of divalent levels, their influx and time course, and consideration of the interaction between different aspects of transmitter release, such as between PPF and the initial probability of release. This approach was invaluable here in understanding the varied effects of strontium on synaptic transmission.

\section{REFERENCES}

Abdul-Ghani MA, Valiante TA, Pennefather PS (1996) $\mathrm{Sr}^{2+}$ and quantal events at excitatory synapses between mouse hippocampal neurons in culture. J Physiol (Lond) 495:113-125.

Atluri PP, Regehr WG (1996) Determinants of the time course of facilitation at the granule cell to Purkinje cell synapse. J Neurosci 16:5661-5671.

Atluri PP, Regehr WG (1998) Delayed release of neurotransmission from cerebellar granule cells. J Neurosci 18:8214-8227.

Augustine GJ, Eckert R (1984) Divalent cations differentially support transmitter release at the squid giant synapse. J Physiol (Lond) 346:257-271.

Augustine GJ, Charlton MP, Smith SJ (1985) Calcium entry and transmitter release at voltage-clamped nerve terminals of the squid. J Physiol (Lond) 369:163-181.

Bain AI, Quastel DMJ (1992) Quantal transmitter release mediated by strontium at the mouse motor nerve terminal. J Physiol (Lond) 450:63-87.

Barrett EF, Stevens CF (1972) The kinetics of transmitter release at the frog neuromuscular junction. J Physiol (Lond) 227:691-708.

Behrends JC, ten Bruggencate G (1998) Changes in quantal size distributions upon experimental variations in the probability of release at striatal inhibitory synapses. J Neurophysiol 79:2999-3011.

Bekkers JM, Clements JD (1999) Quantal amplitude and quantal variance of strontium-induced asynchronous EPSCs in rat dentate granule neurons. J Physiol (Lond) 516:227-248.

Bellingham MC, Walmsley B (1999) A novel presynaptic inhibitory mechanism underlies paired pulse depression at a fast central synapse. Neuron 23:159-170.

Borst JGG, Sakmann B (1996) Calcium influx and transmitter release in a fast CNS synapse. Nature 383:431-434.

Chen C, Regehr WG (1999) Contributions of residual calcium to fast synaptic transmission. J Neurosci 19:6257-6266.

Choi S, Lovinger DM (1997) Decreased frequency but not amplitude of quantal synaptic responses associated with expression of corticostriatal long-term depression. J Neurosci 17:8613-8620.

Creager R, Dunwiddie T, Lynch G (1980) Paired-pulse and frequency facilitation in the CA1 region of the in vitro rat hippocampus. J Physiol (Lond) 299:409-424.

Cummings DD, Wilcox KS, Dichter MA (1996) Calcium-dependent paired-pulse facilitation of miniature EPSC frequency accompanies depression of EPSCs at hippocampal synapses in culture. J Neurosci 16:5312-5323.

Dobrunz LE, Stevens CF (1997) Heterogeneity of release probability, facilitation, and depletion at central synapses. Neuron 18:995-1008.

Dodge FA, Rahamimoff R (1967) Co-operative action of calcium ions in transmitter release at the neuromuscular junction. J Physiol (Lond) 193:419-432.

Dodge FAJ, Miledi R, Rahamimoff R (1969) Strontium and quantal release of transmitter at the neuromuscular junction. J Physiol (Lond) 200:267-283.

Feng TP (1941) Studies on the neuromuscular junction. Chin J Physiol 16:341-372.

Fogelson AL, Zucker RS (1985) Presynaptic calcium diffusion from various arrays of single channels. Implications for transmitter release and synaptic facilitation. Biophys J 48:1003-1017.

Glantz SA (1997) Primer of biostatistics. New York: McGraw-Hill.

Goda Y, Stevens CF (1994) Two components of transmitter release at a central synapse. Proc Natl Acad Sci USA 91:12942-12946.

Heidelberger R, Heinemann C, Neher E, Matthews G (1994) Calcium dependence of the rate of exocytosis in a synaptic terminal. Nature 371:513-515.

Kamiya H, Zucker RS (1994) Residual $\mathrm{Ca}^{2+}$ and short-term synaptic plasticity. Nature 371:603-606.

Lando L, Zucker RS (1994) $\mathrm{Ca}^{2+}$ cooperativity in neurosecretion measured using photolabile $\mathrm{Ca}^{2+}$ chelators. J Neurophysiol 72:825-830.

Lévénès C, Daniel H, Soubrié P, Crépel F (1998) Cannabinoids decrease excitatory synaptic transmission and impair long-term depression in rat cerebellar Purkinje cells. J Physiol (Lond) 510:867-879.

Li C, Davletov BA, Südhof TC (1995) Distinct $\mathrm{Ca}^{2+}$ and $\mathrm{Sr}^{2+}$ binding properties of synaptotagmins. Definition of candidate $\mathrm{Ca}^{2+}$ sensors for the fast and slow components of neurotransmitter release. J Biol Chem 270:24898-24902.

Lipp P, Niggli E (1994) Sodium current-induced calcium signals in isolated guinea-pig ventricular myocytes. J Physiol (Lond) 474:439-446.

Llano I, Marty A, Armstrong CM, Konnerth A (1991) Synaptic- and agonist-induced excitatory currents of Purkinje cells in rat cerebellar slices. J Physiol (Lond) 434:183-213.

Manabe T, Wyllie DJ, Perkel DJ, Nicoll RA (1993) Modulation of synaptic transmission and long-term potentiation: effects on paired pulse facilitation and EPSC variance in the CA1 region of the hippocampus. J Neurophysiol 70:1451-1459.

McNaughton BL (1982) Long-term synaptic enhancement and shortterm potentiation in rat fascia dentata act through different mechanisms. J Physiol (Lond) 324:249-262.

Meiri U, Rahamimoff R (1971) Activation of transmitter release by strontium and calcium ions at the neuromuscular junction. J Physiol (Lond) 215:709-726.

Mellow AM, Perry BD, Silinsky EM (1982) Effects of calcium and strontium in the process of acetylcholine release from motor nerve endings. J Physiol (Lond) 328:547-562.

Miledi R (1966) Strontium as a substitute for calcium in the process of transmitter release at the neuromuscular junction. Nature 212:1233-1234.

Mintz IM, Sabatini BL, Regehr WG (1995) Calcium control of transmitter release at a cerebellar synapse. Neuron 15:675-688.

Morishita W, Alger BE (1997) $\mathrm{Sr}^{2+}$ supports depolarization-induced suppression of inhibition and provides new evidence for a presynaptic expression mechanism in rat hippocampal slices. J Physiol (Lond) 505:307-317.

Oliet SHR, Malenka RC, Nicoll RA (1996) Bidirectional control of quantal size by synaptic activity in the hippocampus. Science 271:1294-1297.

Otis TS, Kavanaugh MP, Jahr CE (1997) Postsynaptic glutamate transport at the climbing fiber-Purkinje cell synapse. Science 277:1515-1518.

Palay SL, Chan-Palay V (1974) Cerebellar cortex. New York: Springer.

Rahamimoff R (1968) A dual effect of calcium ions on neuromuscular facilitation. J Physiol (Lond) 195:471-480.

Rahamimoff R, Yaari Y (1973) Delayed release of transmitter at the frog neuromuscular junction. J Physiol (Lond) 228:241-257.

Regehr WG, Atluri PP (1995) Calcium transients in cerebellar granule cell presynaptic terminals. Biophys J 68:2156-2170.

Roberts WM, Jacobs RA, Hudspeth AJ (1990) Colocalization of ion channels involved in frequency selectivity and synaptic transmission at presynaptic active zones of hair cells. J Neurosci 10:3664-3684.

Rumpel E, Behrends JC (1999) $\mathrm{Sr}^{2+}$-dependent asynchronous evoked transmission at rat striatal inhibitory synapses in vitro. J Physiol (Lond) 514:447-458.

Sabatini BL, Regehr WG (1995) Detecting changes in calcium influx which contribute to synaptic modulation in mammalian brain slice. Neuropharmacology 34:1453-1467.

Sabatini BL, Regehr WG (1997) Control of neurotransmitter release by presynaptic waveform at the granule cell to Purkinje cell synapse. J Neurosci 17:3425-3435. 
Sabatini BL, Regehr WG (1998) Optical detection of presynaptic calcium currents. Biophys J 74:1549-1563.

Simon SM, Llinas RR (1985) Compartmentalization of the submembrane calcium activity during calcium influx and its significance in transmitter release. Biophys J 48:485-498.

Van Der Kloot W, Molgo J (1993) Facilitation and delayed release at about $0^{\circ} \mathrm{C}$ at the frog neuromuscular junction: effects of calcium chelators, calcium transport inhibitors, and okadaic acid. J Neurophysiol 69:717-729.

Xu-Friedman MA, Regehr WG (1999) Presynaptic strontium dynamics and synaptic transmission. Biophys J 76:2029-2042.

Yawo H (1999) Two components of transmitter release from the chick ciliary presynaptic terminal and their regulation by protein kinase $\mathrm{C}$. J Physiol (Lond) 516:461-470.

Zengel JE, Magleby KL (1980) Differential effects of $\mathrm{Ba}^{2+}, \mathrm{Sr}^{2+}$, and
$\mathrm{Ca}^{2+}$ on stimulation-induced changes in transmitter release at the frog neuromuscular junction. J Gen Physiol 76:175-211.

Zengel JE, Magleby KL (1981) Changes in miniature endplate potential frequency during repetitive nerve stimulation in the presence of $\mathrm{Ca}^{2+}$, $\mathrm{Ba}^{2+}$, and $\mathrm{Sr}^{2+}$ at the frog neuromuscular junction. J Gen Physiol 77:503-529.

Zhao M, Hollingworth S, Baylor SM (1996) Properties of tri- and tetracarboxylate $\mathrm{Ca}^{2+}$ indicators in frog skeletal muscle fibers. Biophys $\mathrm{J}$ 70:896-916.

Zucker RS (1999) Calcium- and activity-dependent synaptic plasticity. Curr Opin Neurobiol 9:305-313.

Zucker RS, Lara-Estrella LO (1983) Post-tetanic decay of evoked and spontaneous transmitter release and a residual-calcium model of synaptic facilitation at crayfish neuromuscular junctions. J Gen Physiol 81:355-372. 